\title{
EI terme pretopònim en el DECat de Joan Coromines
}

\author{
Maria-Reina Bastardas i Rufat \\ Universitat de Barcelona \\ reina.bastardas@ub.edu
}

Resum: En aquest article es traça breument la història de la introducció del terme pretopònim en els estudis sobre la història del lèxic català i l'onomàstica catalana. També, de la seva difusió a la terminologia filològica d'altres llengües veïnes. S'intenta analitzar l'ús que en fa Coromines en el DECat de cara a intentar una definició del terme.

Paraules clau: lexicografia; metalexicografia; història de la terminologia; DECat; GMLC.

Abstract: This essay draws the history of the Catalan word pretoponim (i. e. pre-toponym) and its introduction in the studies on the history of Catalan words and place-names. It also deals with the introduction of this word in the scientific terminology of neighbouring languages (Spanish, French). And, finally, it analyses the use of this word in Coromines' DECat as a step towards its exact definition.

Keywords: Lexicography; Metalexicography; History of Terminology; DECat; GMLC. 



\section{Presentació}

En aquest article ens proposem, després de fer un breu recorregut, més aviat impressionista, per la història del mot pretopònim en la llengua catalana i en algunes llengües veïnes, de veure com Coromines l'usa en el seu gran diccionari etimològic (DECat). Aquest treball hauria de servir per acostar-nos a una definició concreta del terme ${ }^{1}$.

\section{El terme pretopònim}

En els diccionaris catalans de referència (DIEC, GDLC) no hi apareix el terme pretopònim, ni tampoc pre-topònim ${ }^{2}$. No sembla que el mot s'hagi introduït tampoc en els repertoris lexicogràfics d'altres llengües: no apareixen les formes que podrien ser els seus paral·lels en francès, italià o espanyol en diccionaris com el TLFi, el GDLI, o el DRAE.

Tanmateix és un mot que ha tingut un ús relativament continuat entre els estudiosos que s'han dedicat a l'estudi de l'onomàstica i de la llengua antiga en general; i, segons es veu, això particularment en català. No podem aquí fer un inventari exhaustiu de les publicacions en català on ha aparegut aquest terme, cosa que d'altra banda exigiria fer un despullament sistemàtic molt fora del nostre abast, però sí que en podem fer una mica d'història i donar-ne algunes pinzellades.

Anant enrere en el temps, trobem el terme en la p. XXIV de la "Introducción" a la publicació del primer fascicle del GMLC. Tenint en compte que es tracta d'una text redactat vers $1960^{3}$, lògicament la llengua emprada és el castellà. El text que hi trobem diu, després d'explicar que en el GMLC no s'hi recullen topònims si no és que permetin de documentar un nom comú: "Por otra parte, el límite entre un topográfico y un topónimo es a menudo difícil de precisar; de ahí el uso frecuente que

\footnotetext{
${ }^{1}$ Agraïm a Ana Gómez Rabal (GMLC - CSIC) i a Julia Alletsgruber les seves informacions personals i el facilitar-nos l'accés a alguns materials.

${ }^{2}$ D'acord amb les propostes de l'IEC sobre l'ús del guionet, optem per usar el terme pretopònim sense guionet, tot i que en les citacions, naturalment, utilitzarem les grafies que trobem en els textos citats.

${ }^{3}$ El primer fascicle del GMLC va aparèixer sense introducció, pròleg o cap altre paratext similar. La “introducción” es va publicar en el fascicle de l'any 1985 (dotalis-dux) però la seva redacció és anterior, creiem que contemporània a la publicació dels primers fascicles; en canvi, el "prefaci / prefacio" (bilingüe) que acompanya també el fascicle dotalis-dux sí que està datat de desembre de 1985.
} 
hacemos del término "pretopónimo"'. I, efectivament, el mot és d'ús freqüent en la redacció del GMLC. Encara que, com hem indicat en la nota 3, la "Introducción" no es va imprimir fins a 1985, en el primer fascicle de l'any 1960 ja hi apareix diverses vegades el terme pretopónimo (tot just iniciar el volum a l'article abbatialis, columna 3; i després a albareda nota 2, aerola, artica, etc). De fet, hi ha una certa consciència en la tradició oral dels propis col·laboradors del GMLC que el terme es va crear en aquest entorn científic. I, lògicament, es troba sovint en les publicacions que d'una manera o altra es relacionen amb el GMLC (vegeu, per exemple, darrerament Gómez Rabal, 2010: 102, n.12; 104, n. 29; o, prou més anys enrere, Bastardas, 1994).

Moreu, en la seva introducció a la toponímia catalana (1982: 20), indica, enmig d'una explicació feta en to ben didàctic de com un nom comú pot esdevenir un topònim: "En una etapa que correspon a la situació intermediària que mena del nom comú a la categoria de nom propi (algú ha anomenat 'pretopònims' aquestes unitats lingüístiques en evolució, quan els 'corònims' -generalment descriptius geogràficsvan esdevenint 'topònims')". Moreu no especifica, però, qui és aquest "algú" que ha usat aquest terme.

En canvi, uns anys més tard ${ }^{4}$, el mateix autor usa pretopònim ja sense cap explicació i aparentment considerant que serà entès sense problema. Moreu (1991: 67), comentant els topònims que apareixen en formacions cognominals en l'antroponímia dels segles X i XI, explica que sovint van introduïts per la preposició de (ex. Isarnus de Cabouez a. 1043) i alguns "poden portar l'antic article salat: Compagno de ipsa Guardia (a. 1025, CSC); Aithii de ipsis Garricis (a. 1025; CSC), Guilabert de ipsa Tonna (a. 1077, 1086; LA), Arnallus Raimundi de ipso Pugol (a. 1095; LA), aquests darrers del Pla de Barcelona. L'article s'explica per la situació de pre-topònims d'uns noms genèrics"'s. Posteriorment, molts autors de reculls toponímics i d'articles al Butlletí de la Societat d'Onomàstica han usat el terme també sense més explicacions (vegeu per exemple, Amigó / Anglès, 2001: 439 "És un nom comú, utilitzat com a pretopònim, amb què es designava el riu Gorg").

\footnotetext{
${ }^{4}$ La publicació del llibre és de 1991. No obstant es tracta d'un recull d'articles; concretament, l'article que mencionem és de 1985. Hem tingut ocasió de comprovar que el terme i la frase citada ja apareixen de manera idèntica en la publicació original.

${ }^{5}$ Les sigles cal llegir-les com a Cartulari de Sant Cugat del Vallès (CSC) i Libri Antiquitatum (de la Catedral de Barcelona), respectivament.
} 


\section{Intents de definició}

Algunes de les publicacions que acabem de mencionar ofereixen una definició, més o menys matisada, a costat del terme pretopònim. Altres, no. Tant una cosa com l'altra són significatives perquè mostren la consciència d'uns autors sobre l'ús d'un mot no admès en el diccionari normatiu i potser no conegut pels lectors; o, a la inversa, mostra la consciència que, segons el criteri de l'autor, el mot és prou habitual com per no necessitar de més explicacions.

Hem vist que Moreu (1982: 20) proposava una explicació segons la qual el pretopònim seria una 'unitat lingüística en evolució en una etapa que correspon a la situació intermediària que mena del nom comú a la categoria de nom propi'. Abans el GMLC no havia proposat exactament una definició però considerava que els pretopònims estaven al "límit entre un [substantiu descriptiu] topogràfic i un topònim".

En principi, una definició així d'aquest terme no pressuposa res respecte a cronologia dels fets que estem tractant. La creació de topònims es pot produir en qualsevol etapa de la llengua, del català preliterari a la llengua actual. Però, com dèiem, el terme sembla haver nascut més aviat en els estudis de tipus històric. Per tant, sovint a les explicacions sobre aquest terme s'hi afegeixen altres consideracions, com el tipus de construcció sintàctica en què solen aparèixer els pretopònims en la documentació del català preliterari ${ }^{6} \mathrm{o}$ sobre la presència i funció de l'article definit en els topònims ${ }^{7}$.

\section{Presència en altres llengües}

Com hem dit més amunt a l'inici d'aquest article (2), el que podrien ser equivalents al terme català pretopònim en altres llengües romàniques no ha entrat en les obres lexicogràfiques de referència. Naturalment no podem fer un despullament sistemàtic d'obres de tema onomàstic en

\footnotetext{
${ }^{6}$ Referències a les fórmules in loco quem dicunt i altres de similars en la documentació llatinomedieval.

7 Sobre això darrer vegeu particularment Chambon 2000 (paràgraf 3.2.) i Chambon 2005, que proposa fer retrocedir la creació de noms de lloc sense article definit com a mínim al voltant de l'any 700 , tenint en compte les dades de la gramàtica històrica que fan obligatori l'article a partir d'aquesta data. Això per la Gal·loromània; no sabem que s'hagi fet un estudi paral·lel pel cas del català.
} 
espanyol, francès, italià, gallec o altres. Tanmateix, a partir de lectures puntuals, hem fet algunes anotacions. El mot el trobem usat, amb una interessant precisió metalingüística, en francès (pré-toponyme); Julia Alletsgruber (2009: 7) escriu: "Nous parlerons donc de quasitoponyme, ou plus justement, avec certains linguistes catalans, de prétoponyme, qui peut se figer en nom propre ou non". Segons l'amable comunicació personal de l'autora sabem que el terme l'ha pres i fet seu a partir de lectures de textos catalans i de lingüistes catalans com el DECat, però que no és usual en els estudis de toponímia francesa, o, si més no, no ho era fins a 2009.

En el cas de l'espanyol pretopónimo val a dir que el mot es troba lògicament usat per autors catalans que escriuen en aquesta llengua (vegeu per exemple, Rosselló Verger, 2010: 24 [glossant Moreu, 1982, que hem citat més amunt, en un text en castellà però publicat a Galícia]; Bastardas, 1998: 44 [en nota, precisant que és un ús del DECat i altres estudiosos]), però també en altres casos.

Ja fa alguns anys, el mot apareixia en la tesi de Carlos Rizos Jiménez Toponimia de la Baja Ribagorza Occidental, llegida a la Universitat de Lleida el 2011, amb una definició: "Durante esa fase intermedia en la que el topónimo se está gestando o se está consolidando se dice que es un pretopónimo" (p. 479)

El trobem usat sovint per Maurilio Pérez González en publicacions relacionades amb el llatí medieval del Regne de Lleó; per exemple, Pérez González (2007: 73), al·ludint a la publicació d'una altra autora, "negar la categoría de topónimo al ejemplo de 1082, que no obstante ella considera un apelativo o, en todo caso, un pretopónimo con el sufijo abundancial -aria". En la introducció a l'obra que dirigeix, Lexicon latinitatis medii aevi regni Legionis (Pérez González, 2010: IX-XI), hi ha una explicació sobre el pas de l'apel·latiu al topònim i altres qüestions d'aquest tipus. En transcrivim una part significativa perquè creiem que és molt interessant:

En el pasado de cada topónimo generalmente ha habido una fase en la que fue un apelativo, es decir, un nombre que aludía a las realidades relacionadas con las características del lugar que convenían a todas las

\footnotetext{
${ }^{8}$ Consultable a partir de la base de dades "Tesis doctorales en red" http://www.tdx.cat/ handle/10803/8175.
} 
cosas de una misma clase. Pero entre ambos extremos (la aplicación de un nombre a un lugar y su consolidación como topónimo) solía haber una fase intermedia en la que el nombre todavía no era reconocido por la comunidad como aplicado a un lugar, es decir, era pretopónimo. Así pues, apelativo, pretopónimo y topónimo son tres fases sin solución de continuidad. Decidir cuándo un nombre de lugar ya se ha consolidado como topónimo es difícil, sobre todo en sociedades como la medieval".

Seguidament, Pérez González sistematitza les "situaciones gramaticales en las que se producen topónimos". Citem també en extens:

1) Compl. Predicativos de verbos en forma persona, participios o sustantivos con la acepción de "llamar(se), nombrar(se), decir(se)": a) de verbos en forma personal como dicunt, dicitur, uocitant, uocitatur, nuncupant, nuncupatur, appellant, appellatur ... b) De participios como nominatus, predictus, prenominatus, uocitatus ... c) De sustantivos como uocabulo/a o de uocabulum est.

Tales compl. predicativos pueden ir introducidos por Ø/ad/in/de/geniti$v o$, pero es dudoso, sobre todo en el caso de b), que sean ya topónimos si van precedidos por $a d /$ in. $^{9}$

I després d'exemplificar els diferents grups, continua:

2) Combinaciones sobre un apelativo genérico: a) Un nombre genérico + adjetivo origina (casi siempre) un topónimo compuesto [...] b) Un nombre genérico + sustantivo origina un topónimo en la segunda parte del compuesto, raras veces en la primera parte [...] c) Un nombre genérico $+d e+$ sustantivo origina (casi siempre) un topónimo en la segunda parte, raras veces en la primera parte.

El mot pretopónimo certament no és en el DRAE o en el diccionari de Lázaro Carreter (1968) i, com veiem, apareix o bé en autors provinents de l'àmbit català o bé en autors que treballen en l'àmbit del llatí medieval i coneixen el GMLC.

\footnotetext{
${ }^{9}$ Totes aquestes explicacions Emilio Nieto Ballester les considera "todo ello [...] demasiado vago y sutil al tiempo" (ressenya a la ZrPh 129 (2013), 534).
} 


\section{Pre-topònim (pretopònim) en el DECat de Joan Coromines}

El terme pretopònim (en realitat en aquella època pretopónimo, en castellà), gestat segons que sembla en el marc del GMLC, va ser ràpidament fet seu per Coromines. El trobem ja des del primer volum del DECat (1980) i sens dubte haurà estat aquesta obra la que haurà contribuït més a difondre'l.

Per estudiar l'ús del terme en el DECat de Joan Coromines, hem espigolat la seva presència en diversos volums, no tots, de l'obra. Hem pres els dos primers volums, ja que hauria de ser aquí on es trobés una definició del terme, si és que l'autor la considerava necessària. I també els volums 4, 6, i 8. Això representa la meitat dels volums de l'obra i, per tant, sembla prou significatiu. De totes maneres, és ben evident que algunes, o moltes, ocurrències ens poden haver passat per ull.

Les estadístiques són les que presentem a continuació.

\begin{tabular}{|c|c|c|}
\hline $\begin{array}{l}\text { volum } 1 \\
\text { A-BL (1980) }\end{array}$ & pretopònim: 1 ocurrència & s.v. artiga, p. $438^{10}$ \\
\hline $\begin{array}{l}\text { volum } 2 \\
\text { BO-CU (1981) }\end{array}$ & $\begin{array}{l}\text { pre-toponímic: } 3 \text { ocurrències } \\
\text { pretopònim: } 1 \text { ocurrència }\end{array}$ & $\begin{array}{l}\text { s.v. caicó p. } 397 \text {; s.v. cam- } \\
\text { bra p. } 451 \text {; s.v. cocó p. } \\
794 ; \text { s.v. coromina p. } 943 ; \\
\text { s.v. culla p. } 1101 / / \\
\text { s.v. cald p. } 422 ; \text { s.v. canya } \\
\text { p. } 496 \text {; s.v. castell p. } 626 / / \\
\text { s.v. coldre p. } 818\end{array}$ \\
\hline $\begin{array}{l}\text { volum } 4 \\
\text { FL-LI (1984) }\end{array}$ & $\begin{array}{l}\text { pre-topònim: } 4 \text { ocurrències } \\
\text { pretopònim: } 2 \text { ocurrències }\end{array}$ & $\begin{array}{l}\text { s.v. gavarra p. } 429 ; \text { s.v. } \\
\text { grava p. } 632 ; \text { s.v. heura p. } \\
\text { 788; s.v. hoste p. } 824 \text { // } \\
\text { s.v. greda p. } 633 \text { i } 634\end{array}$ \\
\hline $\begin{array}{l}\text { volum } 6 \\
\text { O-QU (1984) }\end{array}$ & pre-topònim: 2 ocurrències & $\begin{array}{l}\text { s.v. péixer p. } 383 \text {; s.v. } \\
\text { popa p. } 696\end{array}$ \\
\hline $\begin{array}{l}\text { volum } 8 \\
\text { SOG-UX } \\
(1988)\end{array}$ & $\begin{array}{l}\text { pre-topònim(s): } 3 \text { ocurrències } \\
\text { pre-toponimic: } 1 \text { ocurrència } \\
\text { pretopònim: } 2 \text { ocurrències }\end{array}$ & $\begin{array}{l}\text { s.v. tallar p. } 237 \text {; s.v. taula } \\
\text { p. } 351 \text {; s.v. tegell p. } 370 / / \\
\text { s.v. tarter o tartera p. } 327 / / \\
\text { s.v. sort p. } 98 \text {; s.v. trilla p. } \\
740\end{array}$ \\
\hline
\end{tabular}

${ }^{10}$ El mot es troba a final de línia, de manera que no es pot saber si la grafia volguda és amb guionet o sense. 
En el que sembla que és la primera aparició del terme pretopònim en el DECat $(1,438)$ no s'hi dóna cap explicació. La frase es refereix a quatre ocurrències del mot artiga "quatre més com a NL o pretopònim" que el DECat cita a partir del GMLC ${ }^{11}$. D'altra banda, en el mateix volum $(1,810)$ hi apareix una altra forma que també ens pot interessar; en l'article bisbe i parlant del valencià diu que la forma castellana obispo és tan estesa que la forma genuïna ha deixat d'usar-se malgrat que Garcia Girona la documenti i comenta Coromines "es deu referir en bona part als usos petrificats i semi-toponímics com aquest de Morvedre [Casa del Bispe, 1962] i la Cova'l Bisbe cap al Broseral a Cabanes de l'Arc (1961)". El terme semi-toponímic sembla també referir-se a un mot fixat com a designació d'un lloc i que ha deixat, o està deixant, de ser entès com a apel $\cdot$ latiu $^{12}$.

En els volums següents, sobretot en el 2, les ocurrències de pretopònim són molt més freqüents. N'hem fet un inventari que intentarem classificar segons alguns criteris. Com mencionàvem més amunt, el procés de creació d'un topònim en principi no hauria de circumscriure's a cap àmbit cronològic. Tanmateix, com hem dit, sembla que en les primeres publicacions on s'ha usat el terme eren en el context de l'estudi del llatí medieval i el català preliterari. Però el fet és que Coromines fa servir, fins i tot de manera majoritària, el terme pretopònim referint-se a materials contemporanis ja sigui escrits o producte de les seves enquestes orals.

Els casos on el fa servir referit als orígens de la llengua són, a més de l'esmentat més amunt en el volum 1 (s.v. artiga), els següents:

"[calder] ja Balari documentà des de molt antic, encara en estat apellatiu i pre-toponímic" $(2,422)$

"[castellar] en docs. arcaics, mig llatins, conserva un valor més viu, apel·latiu o pre-toponímic" $(2,626)$

" 1 a documentació gavarra com a pre-topònim 1088, com a nom comú en un text del XIV o XV" $(4,429)$.

\footnotetext{
${ }^{11}$ En els llocs corresponents on es parla d'albereda (1, 144 s.v. àlber), abadal (1, 8, s.v. abat) i erola $(3,418$, s.v. era) del DECat no es parla del caràcter toponímic o pretoponímic dels exemples del GMLC que hem esmentat en el punt 2 i on el GMLC feia aparèixer el mot pretopónimo.

${ }^{12}$ Cf. l'observació d'Alletsgruber (2009: 5) “il s'agit de la désignation d'un lieu concret, voire d'un quasi-nom de lieu", paral·lel al "semi-toponímic" de Coromines.
} 
En els dos primers el terme pretoponímic s'oposa a apel·latiu, però els dos estan en oposició implícita a topònim. La idea és que el que actualment és un topònim es documenta en la documentació més arcaica "encara" "conservant" un estat com a apel·latiu o pretopònim que cal entendre no com a sinònims sinó que es refereixen als diferents documents mencionats on el mot té una funció o altra.

En canvi, en els casos següents es refereix a unitats que es descriuen com a pretopònims en l'actualitat:

“ "jachère"13 defineixen el pretopònim las kutíbas a Sant Esteve del Monestir [Rosselló]” $(2,818)$

[graver] "El grabé de la Ribera (apel-latiu pre-topònim, Sant Feliu d'Amunt, 1960)" (4, 632)

"CAICÓ val. (Valls de Segó, Llíria, Vilamarxant, Font de la Figuera, 1962 , avui més aviat topònim o pre-topònim que veritable apel·latiu) 'lledoner'” $(2,397)$

"[cambra] 'cova' [...] (molt estès, avui, sobretot com a topònim o pretopònim, en les comarques muntanyoses, etc.).” $(2,451)$

"[canet] per bé que a Mall.[orca] [...] es nota amb valor més pre-toponímic (Alcúdia, 1963) que de topònim i no veig que s'apliqui tant amb el sentit secundari"

"[hedra] I de llarg a llarg del P. Val., en la toponímia, o com a pretopònim, però també com a apel·latiu ben corrent" $(4,788)$

"[greda $]$ En català existeix sobretot com a topònim o pretopònim $[\ldots]$ En toponímia i com a pretopònim, en part en formes aberrants, n'han quedat molts representants i derivats: La Creda, partida prop de Perles (Segre mitjà)" (4, 633-4)

"[descendents de TIGNUM] En català, però, aquest mot no ha persistit més que en NLL o pre-topònims, i en algunes supervivències locals" $(8,370)$

"[coromina i colomina $]$ es presenten en grans masses com a noms genèrics, toponímics, com a pre-topònims o topònims" $(2,943)$

"CULLA, nom de lloc (en part genèric, en part topònim o pre-topònim) freqüent cap a l'Urgellet i el Segre mitjà" $(2,1101)$

[pastural "devesa" propi del Rosselló, Cerdanya i Ripollès] "però, almenys com a pretopònim o genèric, segueix trobant-se per tot el Conflent (Els Pasturals, partida de Cornellà)" (6,383).

"La que ha donat ${ }^{+}$pòpia en la nostra toponímia, on apareix com a genèric o pre-topònim, de turons de forma arrodonida" $(6,696)$

${ }^{13}$ Es pot traduir en català com "guaret". 
"[sort $]$ El sentit bàsic de parcel·la de terra es troba avui pertot, si més no com a genèric o pretopònim" $(8,98)$

"[trilla] En altres casos, els contextos ens deixen més en dubte, entre veure-hi un nom de lloc, o un pretopònim o genèric" $(8,740)$

"[atall] 'atajo', usual com a genèric o pre-topònim" $(8,237)$

"[tartera] a part dels topònims propis, majors i menors, sovint amb caràcter genèric o pre-toponímic, o merament apel·latiu" $(8,327)$

"[cocó] gran difusió en la toponímia de la major part del País Valencià, com a topònim propi o com a genèric toponímic [...] L'àrea d'extensió del mot és sobretot del Nord i del Centre-Sud del País: constatat, quasi sempre en genèrics i pre-topònims, a Bel, Herbés, Castellfort, etc.” (2, 794)

"[hospital] Es continua usant la forma antiga en es-, vulgarment, i en particular com a pre-topònim o genèric toponímic" $(4,824)$

"[taula] es diu també com a sinònim de bancal, i sovint i apareix convertit en genèric toponímic i fins pre-topònim" $(8,351)$.

En aquest grup hi ha des d'ocurrències que es refereixen a les enquestes orals de Coromines (per exemple, les dues primeres mencionades) fins a tipus toponímics estesos com a microtopònims (coromina, sort, tartera). Observem aquí encara la presència freqüent d'un altre mot que Coromines associa molt sovint a pretopònim (en els 11 casos que citem en darrer lloc): el genèric (com a substantiu la majoria, però també en dos casos com a adjectiu: caràcter genèric, nom genèric) i també genèric toponímic (els tres darrers casos). En realitat de l'ús que se'n fa no queda gaire clar si s'està parlant de quatre categories diferents (en ordre progressiu de fixació en la toponímia: apel-latiu, genèric toponímic, pretopònim, topònim) com sembla per exemple que es dedueixi del darrer exemple mencionat ("genèric toponímic i fins pretopònim") o si genèric és un sinònim o quasi sinònim de pretopònim (com es sembla deduir de "nom de lloc, o un pretopònim o genèric").

La definició que Coromines tenia en ment per aquests termes es veu encara enterbolida perquè sovint els aplica a grups més o menys nombrosos de designacions de lloc que no enumera. Com a exemple reproduïm totalment el paràgraf que el DECat dedica a castellar, ja que la seva extensió reduïda ens permet de fer-ho: 
Castellar 'petit conjunt fortificat' a penes ha quedat més que en la toponímia ${ }^{14}$; en docs. arcaics, mig llatins, conserva un valor més viu, apellatiu o pre-toponímic: Bast.-Bass. [el GMLC] donen moltes cites de castellare des de 986; i amb l'expressada síncope, Castlar > Catllar (freqüentíssim en la Top., junt amb els derivats Catllaràs, Catllarí, un i altre a l'Alt Berguedà).

És clar que per copsar exactament què entén Coromines per ús apellatiu i per ús pretoponímic s'hauria d'analitzar com tracta ell les ocurrències d'aquestes "moltes cites" de "documents arcaics mig llatins" i dir en cada cas a quin ús correspon, però això no és factible perquè les tracta en bloc.

\section{Conclusió}

Aquest estudi, primera aproximació certament provisional, permet perfilar algunes conclusions. 1) L'ús del terme pretopònim sembla haver-se expandit a partir de l'ús que se n'ha fet en els estudis de llatí medieval i del català antic. Concretament, a partir de la redacció, en aquell moment en castellà, del GMLC i ràpidament adaptat al català en les publicacions en aquesta llengua (Coromines des de 1980, Moreu des de 1982). 2) Actualment sembla que és prou estès perquè els estudiosos l'usin sense necessitat d'explicació o glosa, o de justificació. 3) Ha arribat a l'espanyol, a través d'autors catalans o d'autors que treballen en el camp del llatí medieval, i al francès, en aquest darrer cas visiblement com a préstec (lingüístic i conceptual) del català.

També hem pogut concloure que el terme apareix prou abundosament en el DECat de Joan Coromines però la seva delimitació conceptual no acaba de quedar ben establerta, potser precisament perquè es tracta d'un terme que designa un procés actiu i també perquè Coromines sovint l'aplica a grups de denominacions de llocs, en la major part dels casos sense enumerar-les (p. ex. per coromina: "es presenten en grans masses com a noms genèrics, toponímics, com a pre-topònims 0 topònims").

Una definició exacta del terme, i, encara més, una explicitació de les condicions que ha de reunir la denominació d'un lloc perquè es pugui considerar un pretopònim (presència, encara, del mot base com a apel-

\footnotetext{
${ }^{14}$ Corregim el toponímica que es llegeix en aquest passatge, fruit d'un error mecànic.
} 
latiu en la llengua comuna, presència de l'article definit, etc.) i no un topònim o un nom comú seria un desideratum. En aquest sentit, és molt valuosa l'aportació de Maurilio Pérez González que mereixeria, encara, algunes matisacions i, si s'escau, una adaptació al cas del català; també caldria trobar-ne una definició que fos aplicable a qualsevol estadi lingüístic i llengua i no només al llatí medieval.

\section{Referències bibliogràfiques}

Alletsgruber, Julia. 2009. Les déverbaux de (EX)STIRPARE dans la toponymie d'oïl: essai de mise au point. Nouvelle Revue d'Onomastique 51: 3-15. Amigó i Anglès, Ramon \& Pere Anglès, Ramon. 2001. L'Albí i els seus noms. Barcelona: Institut d'Estudis Catalans.

Bastardas i Rufat, Maria-Reina. 1994. La formació dels col-lectius botànics en la toponímia catalana. Barcelona: Reial Acadèmia de Bones Lletres.

Bastardas i Rufat, Maria-Reina. 1998. Aspectos de la toponimia botánica de Asturias. Lletres asturianes 68: 41-55.

Chambon, Jean-Pierre. 2000. Pour la chronologie des toponymes (gallo)romans d'origine délexicale. Étude d'un type tardo-antique aquitain: Fornols. Estudis Romànics 22: 59-82.

Chambon, Jean-Pierre. 2005. Toponymie et grammaire historique: les noms de lieux issus de cappella et forestis et la diffusion spatiale de l'article défini dans la Galloromania. A Jacquart, Danielle; James-Raoul, Danièle \& Soutet, Olivier (ed.) Par les mots et les textes. Mélanges de langue, de littérature et d'histoire des sciences médiévales offerts à Claude Thomasset. París: Université Paris-Sorbonne, 143-155.

DECat $=$ Coromines, Joan. 1980-2001. Diccionari etimologic i complementari de la llengua catalana. Barcelona: Curial/La Caixa.

DIEC $=$ Diccionari de la llengua catalana (2a ed.). Barcelona: Institut d'estudis catalans. http://dlc.iec.cat/ [Accés 20/02/2015].

DRAE = Diccionario de la lengua española . Madrid: Real Academia Española. http://www.rae.es/recursos/diccionarios/drae [Accés 20/02/2015].

GDLC $=1998$. Gran diccionari de la llengua catalana . Barcelona: Enciclopèdia Catalana.

GDLI = Battaglia, Salvatore. 1961-2002. Grande dizionario della lingua italiana. Torino: UTET.

GMLC = Glossarium mediae latinitatis Cataloniae ab anno DCCC usque ad annum MC, conditum ab M. Bassols de Climent; conficiendum curavit Iohannes Bastardas. Barcelona: CSIC, 1960-- 
Gómez Rabal, Ana, 2010. Léxico y cronología: la primera datación de las voces catalanas. De Coromines al Glossarium Mediae Latinitatis Cataloniae. Zeitschrift für romanische Philologie 126: 98-114.

Lázaro Carreter, Fernando. [1953] 1968. Diccionario de términos filológicos. Madrid: Gredos.

Moreu-Rey, Enric. 1982. Els nostres noms de lloc. Mallorca: Editorial Moll (Els treballs i els dies; 22).

Moreu-Rey, Enric. 1991. Antroponímia. Història dels nostres prenoms, cognoms i renoms. Barcelona: Universitat de Barcelona.

Pérez González, Maurilio. 2007. La voz bolonera o bollonera en el latín medieval diplomático asturleonés. Voces (Universidad de Salamanca) 18: 69-80.

Pérez González, Maurilio (dir.). 2010. Lexicon latinitatis medii aevi regni Legionis (s. VIII-1230) imperfectum / Léxico latinorromance del reino de León (s. VIII-1230). Turnhout: Brepols.

Rosselló Verger, Vicenç. 2010. Toponimia, geografía y cartografía. En Sousa Fernández, Xulio (ed.) Toponimia e cartografía. Santiago de Compostela: Instituto da Lingua Galega, 23-37.

TLFi = Trésor de la langue française informatisé. http://atilf.atilf.fr/ [Accés 20/02/2015]. 